\title{
BREEDING ACTIVITIES OF THE PIG-TAILED MACAQUE (MACACA LEONINA) IN BANGLADESH
}

\author{
M.M. Feeroz \\ Wildlife Research Group, Department of Anatomy, University of Cambridge, UK. \\ Email:
}

\begin{abstract}
Breeding activities of Pig-tailed Macaques (Macaca leonina) were studied from May 1996 to September 1997 in the West Bhanugach Forest Reserve of Bangladesh. This species is not a seasonal breeder and breeding activities and births were recorded throughout the year. Swelling of the sexual skin is most important signal of female receptivity in this species. Both copulatory and non-copulatory mounts were observed. Most copulation were single mount $(66.3 \%)$ and some were multi-mount. Overall, $62 \%$ adult females of the study area gave birth during this period.
\end{abstract}

\section{Keywords}

Bangaldesh, Birth, copulation, Macaca leonina, mating, Pig-tailed Macaque

\section{Introduction}

It is not easy to gain adequate understanding of a social species' ecology and evolution without a detailed knowledge of its sexual contacts under more or less natural conditions (Kaufmann, 1965). Macaques are widely distributed, ranging from tropical to cool temperate zones (Fleagle, 1988). Their behaviour and social structure might be related to differences in their habitats (Mah, 1980; Shiveley et al., 1982; Thierry, 1985; Caldecott, 1986) and mating seasonality is related to the environment (van Schaik \& van Noordwijk, 1985; Lindburg, 1987). At the onset of breeding several changes are observed in females of which swelling of the sexual skin is most important. In some species swelling is observed synchronously in all adult females of the group (seasonal breeder) while swelling is observed asynchronously among the adult females (Macaca leonina) of the group in some species ie., adult females of the group become receptive in different times of the year (year round breeder; Oi, 1996). Since female receptivity plays an important role in determining the number of males in the group
(Trivers,1972; Bernstein \& Wade, 1983; Ridley, 1986; Oi, 1996) study of the breeding activities are prerequisite for understanding the social organisation of a species.

The sexual behaviour and mating system of Pig-tailed Macaques (Macaca nemestrina nemestrina) of Indo-malayan region have been studied under laboratory conditions (e.g. Kuehn et al., 1965; Tokuda et al., 1968) and briefly in the wild based on fragmentary observations (Bernstein, 1967; Caldecott, 1986) while detailed in natural forest at the provisioning site in Sumatra (Oi, 1991, 1996). No information is available on the breeding activities of other subspecies of Pig-tailed Macaque (Macaca leonina) in mainland Asia. Breeding activities of this subspecies have been analysed here and hence a comparison can be made with the other subspecies of pig-tailed macaque (Macaca nemestrina nemestrina) as well as with other species of macaques.

\section{Methods}

Study area: The study was conducted in the West Bhanugach Forest Reserve $\left(24^{0} 32^{\prime} \mathrm{N}\right.$ and $91^{\circ} 47^{\prime} \mathrm{E}$; altitude $\left.22 \mathrm{~m}\right)$, situated $7 \mathrm{~km}$ east of Srimangal Upazila headquarter, in the north-east of Bangladesh. The total area is 2,738 ha $(6,760$ acres $)$. This forest is not very markedly evergreen, but the majority of the small trees are evergreen and most of the tall trees are deciduous (Ahsan, 1994; Feeroz, 1999). According to MacKinnon (1997), West Bhanugach Forest Reserve is tropical wet semi-evergreen type. Temperature varies from $4.9^{\circ}$ to $35.5^{\circ} \mathrm{C}$ and monthly rainfall varies from 0 to $573 \mathrm{~mm}$. During this study period four seasons were recognized, viz., winter (December to February), premonsoon (March to May), monsoon (June to September) and post monsoon (October-November).

Data collection: Behavioural data were collected by scan sampling methods (Altmann, 1974), using 15-min intervals. An interval of 15 minutes ensures that each scan is usually independent from the previous one, an essential requirement to

Present address: Department of Zoology, Jahangirnagar University, Savar, Dhaka, Bangladesh 
satisfy conditions for statistical analysis. Data on sexual behaviour of the study species was derived from (1) a group studied for 17 months between May 1996 and September 1997 in the West Bhanugach Forest Reserve; and (2) four other groups studied occasionally (1 day/group /month) in the same site. Quantitative data on duration, intervals and frequencies of mounting were collected through ad libitum notes. Because of the occurrence of sexual and non-sexual mounting in macaques, and the ambiguity between them, the term mounting rather than mating is used and interactions related to mounting have been termed sexual interactions as used in other studies (Oi, 1996). All copulatory mounts were separately recorded from non-copulatory ones. Ejaculation was not seen during copulation, so the number of mounts in a complete series was recorded until the male left the female. If the adult male fed or left the female between mounts, copulation was recorded as a different mounting. Swelling was recorded as either full swelling or beginning of swelling. Thrusts/mounts were also recorded wherever possible.

\section{Results and Discussion}

\section{Female sexual activities}

No distinct season was recorded for sexual activities. Females with sexual swellings were observed throughout the study period and were not concentrated in any particular month; at least one adult female was fully swollen in each month. Initially, the skin around the anus turned red and then it became swollen, but swelling extending to the tail base was not observed, as noted by Oi (1996). Frequency distribution of females with full swelling are shown in Figure 1 on the basis of observation of five groups in the main study site. There is no significant differences between the number of swollen females observed in different months $\left(c^{2}=9.37, \mathrm{df}=15, \mathrm{P}>0.05\right)$, but in one year, the number of swollen females observed in different seasons varied significantly $\left(c^{2}=9.05, \mathrm{df}=3, \mathrm{p}<0.05\right)$ with a peak in the monsoon (between June and September).

Female sexual maturity varied from species to species. Macaques living in broadleaf evergreen forest tend to have a later age at first reproduction than the macaques living in other habitats (Ross, 1992). All pig-tailed females who appeared to have reached 3.5-4 years of age showed swelling of the sexual skin (Fooden, 1975; Oi, 1996). Thereafter, regular menstrual cycles occur within a period of 25 to 40 days (Eaton, 1973; Hadidian \& Bernstin, 1979; Matsumura, 1993; Oi, 1996). Except for Macaca sinica and M. assamensis, perineal swellings are observed in all macaque species (Fooden, 1980). Strongsmelling vaginal discharge has been observed in Macaca sinica and in Macaca radiata (Glick, 1980), and "sharp-smelling" secretion in M. fuscata.

Like other species of macaques, e.g. Macaca silenus (Kumar, 1987), M. sylvenus (Taub, 1980, 1982), M. n. nemestrina (Caldecott, 1986; Oi, 1996), female sexual activities were mainly observed during the follicular phase of the menstrual cycle, i.e. when the imminence of ovulation is revealed by maximum

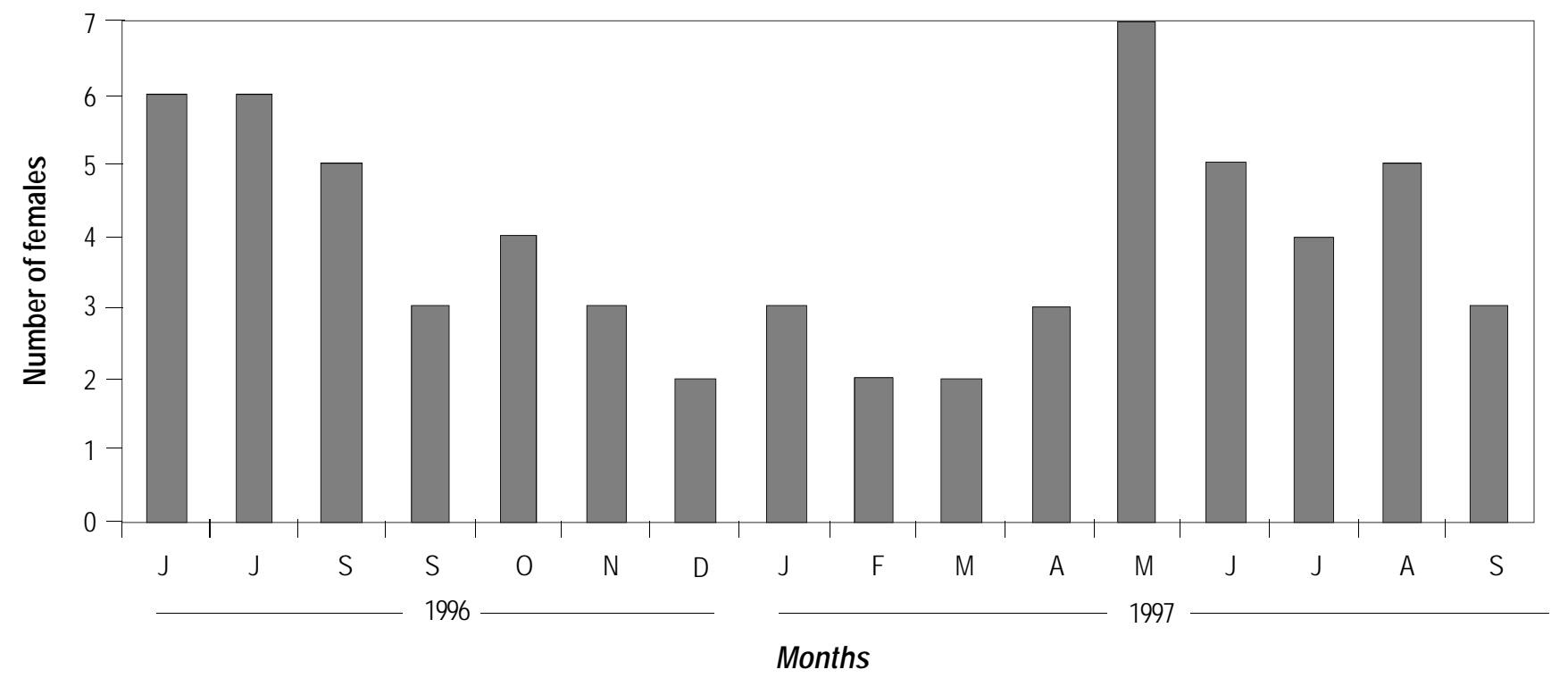

Figure 1. Frequency distribution of fully swollen adult females observed in four groups in the main study site. 
Table 1. Frequency distribution of number of mounts in each series of copulation

\begin{tabular}{lll}
\hline $\begin{array}{l}\text { No. of mounts in a } \\
\text { series of copulation }\end{array}$ & Frequency & \% of observations \\
\hline 1 & 57 & 66.3 \\
2 & 11 & 12.8 \\
3 & 5 & 5.8 \\
4 & 3 & 3.5 \\
5 & 4 & 4.6 \\
6 & 3 & 3.5 \\
7 & 2 & 2.3 \\
8 & 1 & 1.2 \\
Total & 86 & 100 \\
\hline
\end{tabular}

perineal tumescence (fully swollen stage). In this study, most of the solicitations by females were observed during swelling when the adult male was frequently groomed by the swollen female, who spent most of her time near adult male and presented her genitalia to him repeatedly.

\section{Copulation}

Both copulatory and non-copulatory mountings were observed in pig-tailed macaques of the West Bhanugach Forest Reserve. A single mount was observed during each non-copulatory mount, but copulation was observed in one or a series of mounts. The number of mounts in a complete copulation varied from one to eight (Table 1). A total of 166 copulatory mounts were recorded during 86 copulations. Sixty-six percent of copulations were single mount; most of the multi-mounts (23 cases) were observed when the first or second nearest member was either sub-adult male or juvenile male. Copulation was mainly observed between the adult male and swollen female (84.9\%), adult male and non-swollen female (8.1\%), adult male and sub-adult female $(1.2 \%)$, and sub-adult male and swollen female (5.8\%). The number of pelvic thrusts varied from eight to 17 in each mount $($ mean $=11.4, \mathrm{sd} \pm 3.9, \mathrm{n}=43)$.

A total of 114 non-copulatory mountings were observed, where both the participants were recognized; $61 \%$ of these noncopulatory mountings were mutual and the rest (39\%) were performed by force. No non-copulatory mount was observed between the swollen female and other members of the group. Force was applied in the form of biting, scratching and sometimes pressing the monkey down on the branches. Non-

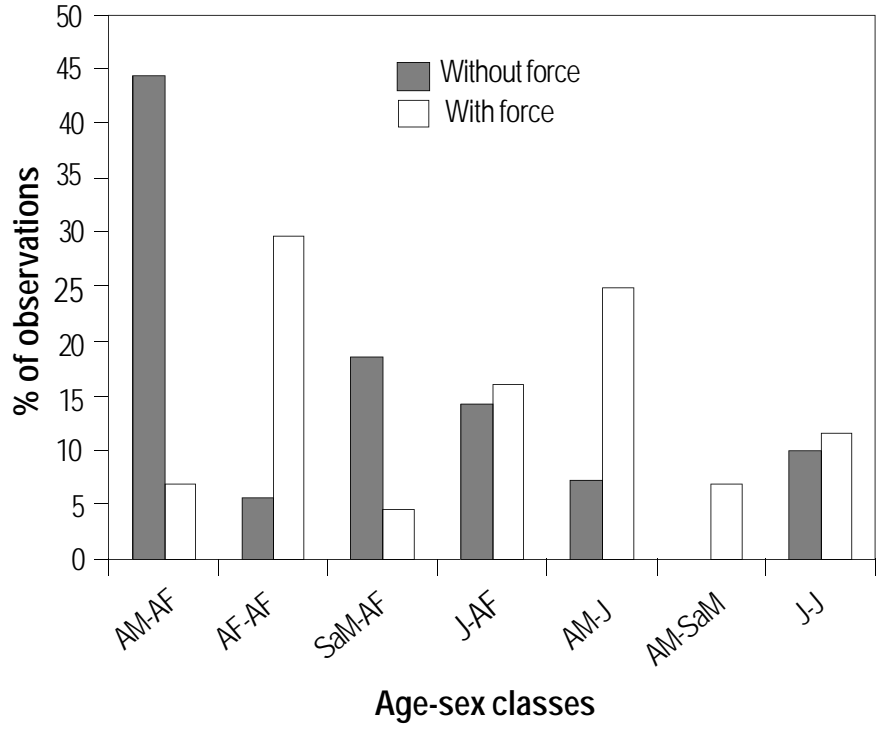

Figure 2. Percentage of observations on non-copulatory mounting by force or without force between different age-sex classes

$A M-A F=$ Adult Male- Adult female; $A F-A F=$ Adult femaleAdult female; SaM-AF = Sub-adult male - Adult female; J-AF = Juvenile - Adult female; $A M-J=$ Adult male - Juvenile; $A M$ SaM = Adult male - Sub-adult male; J-J = Juvenile - Juvenile

copulatory mounts were observed mutually between adult male and adult female in $44.3 \%$ cases, while these mounts were not observed between adult male and sub-adult male without force applied by the adult male (Fig. 2). On the other hand, 29.5\% female-female non-copulatory mounts involved force and in all these cases the dominant female was observed to apply force to the subordinate. Non-copulatory mounting between subadult male and adult female was mutual in $17.3 \%$ cases. No observation was recorded where sub-adult or juvenile male mounted the adult female by force and in all these mounts, subadult or juveniles were solicited by the adult female. Juvenilejuvenile non-copulatory mounting was observed both by mutual cooperation and by force in $10 \%$ and $11.5 \%$ of the cases respectively (Fig. 2). Thus, non-copulatory mounting in pigtailed macaque occurred in the following ways: (1) mutual between adult male and adult female; (2) adult females by force; (3) subordinate males mount high-ranking adult female by soliciting; and (4) young mounting each other both by mutual and force.

Copulatory behaviour varies in different species of macaques. Fooden (1980) classified macaques into four species groups on the basis of their penile structure and suggested that these 
Table 2. Newborn infants recorded in five groups of Pig-tailed macaques in the main study site

\begin{tabular}{|c|c|c|}
\hline No of birth & Approximate date of birth & Group identification \\
\hline 1 & ( \pm 8 days) & Group-3 \\
\hline 2 & $12.7 .1996( \pm 4)$ & Group -5 \\
\hline 3 & $25.9 .1996( \pm 5)$ & Group-4 \\
\hline 4 & $8.10 .1996( \pm 1)$ & Main study group \\
\hline 5 & 2.11.1996 $( \pm 8)$ & Group-2 \\
\hline 6 & 7.11.1996 ( \pm 1$)$ & Main study group \\
\hline 7 & 3.12.1996 (Specific date) & Main study group \\
\hline 8 & $21.12 .1996( \pm 10)$ & Group-3 \\
\hline 9 & $5.12 .1996( \pm 3)$ & Group-5 \\
\hline 10 & 16.1.1997 $( \pm 6)$ & Main study group \\
\hline 11 & 28.1.1997 $( \pm 9)$ & Group-2 \\
\hline 12 & 14.2.1997 $( \pm 5)$ & Group-5 \\
\hline 13 & 8.3.1997 $\quad( \pm 7)$ & Group-4 \\
\hline 14 & 18.4.1997 $( \pm 15)$ & Group-3 \\
\hline 15 & 12.5.1997 $( \pm 5)$ & Main study group \\
\hline 16 & 20.6.1997 ( \pm 12$)$ & Group-4 \\
\hline 17 & 19.7.1997 ( \pm 14$)$ & Group2 \\
\hline 18 & $9.8 .1997 \quad( \pm 2)$ & Group-5 \\
\hline
\end{tabular}

() approximate date of birth within this limit

characteristics are related to mount-ejaculation pattern. Males of some species typically ejaculate at the end of one isolated intromissive mount (single-mount ejaculator) and in some species, males ejaculate during the last series of the mount (multi-mount ejaculator). Fooden's hypothesis was supported by subsequent studies (Shiveley et al., 1982; Caldecott, 1986; Dixson, 1995), but at least two species are now reclassified. Macaca sylvanus (Barbary Macaque) previously considered to be a multi-mount ejaculator, was shown to be a single-mount ejaculator (Taub, 1982), and M. fascicularis (Long-tailed Macaque) previously considered to be multi-mount ejaculator, was found to perform both types of copulation (Shiveley et al., 1982). In this study, Pig-tailed Macaques performed both singlemount and multi-mount ejaculations, with single mount more frequent. Oi (1996) showed that in Sumatra they performed both single- and multi-mount ejaculations with $83.5 \%$ copulation single-mount. Previous laboratory studies suggested that Pigtailed Macaques are multi-mount ejaculators (Tokuda et al., 1968; Nadler \& Rosenblum, 1973). Busse and Estep (1984) suggested that multiple intromissions prior to ejaculation in Pig-tailed Macaques may serve to dislodge copulatory plugs deposited by previous males. Multi-mount ejaculation in the wild Pig-tailed Macaque was reported by Bernstein (1967) and Caldecott (1986), but Bernstein also mentioned that among 113 potentially reproductive mountings, many were in a single copulatory sequence. On the other hand, on only 17 observations, Caldecott concluded that copulation was composed of a series of mounts with an inter-mount interval ranging from 1-20 min. None of his observations were a complete set of mountings, as he stated, because of poor visibility and they are not conclusive, since he could not discern when ejaculation occurred (Oi, 1996).

No infantile copulatory mounting was observed in this study, but it has been reported for various species of macaques (e.g. Macaca nemestrina: Zuckerman, 1932; M. mulatta : Lindburg, 1971; M. arctoides : Trollope \& Jones, 1972). Non-copulatory mounting was observed between the juveniles in this study, but no infant was observed to mount any group members. The pattern and function of the non-copulatory mounts relate to the dominance of the participants. Adult males mounted any members of the group with or without force. Low-ranking subadult or juvenile males were observed to mount high-ranking adult female by prolonged solicitation, but high-ranking adult females were observed to mount low- ranking female and juvenile by force.

\section{Birth}

A total of 16 new-born infants were recorded in five groups of Pig-tailed Macaques at the main study site between June 1996 and June 1997. Another two infants were recorded at other times (July \& August 1997; Table 2); there was no specific birth peak. At least one newborn baby was recorded in each month, except in August 1996 and September 1997. Two infants were recorded in November 1996 and January 1997, while three infants were recorded in December 1996. Overall, 62\% adult females of the five groups gave birth in the WBFR during the study period. It is very difficult to estimate gestation period in the wild. Since each female copulated several times with the adult male throughout the swollen period, specific dates of conception are very difficult to determine. Only once I was able to recognise the female in the main study group that last copulated on 3 December 1996; swelling was not observed again in that female until she gave birth on 12 May 1997. Thus, the gestation period was about 160 days.

\section{Acknowledgements}

I am indebted to Dr. David J. Chivers of the University of Cambridge for his constant support throughout the study period. My studies at Cambridge were supported by an award from the Commonwealth, UK. My field study was partially supported by this award and also by the Lundgren Fund, the 
Newton Trust and the Department of Anatomy, University of Cambridge and a grant from the Cott Fund (Selwyn College). The British Council looked after me during the whole period of my study, both in the UK and in the field.

\section{References}

Ahsan, M.F. (1994). Behavioural ecology of the Hoolock Gibbon in Bangladesh. Unpubl. Ph.D thesis. Univ. of Cambridge, Cambridge.

Altmann, J. (1974). Observational study of behaviour: sampling methods. Behaviour 49: 222-267.

Bernstein, I.S. (1967). A field study of the Pig-tailed Monkey (Macaca nemestrina). Primates 8: 217-228.

Bernstein, I.S. and T.D. Wade (1983). Intrasexsual selection and male mating strategies in baboons and macaques. International Journal of Primatology 4: 201-235.

Busse, C.D. and D.Q. Estep (1984). Sexual arousal in male pig-tailed monkeys (Macaca nemestrina): effects of serial matings by two males. J. Comp. Psychol. 98: 227-231.

Caldecott, J.O. (1986). An ecological and behavioural study of the pigtailed macaque. Contrib. primatol. Vol. 21. S. Karger, Basel.

Dixson, A.F. (1995). Sexual selection and ejaculatory frequencies in primates. Folia primatol. 64: 146-152.

Eaton, G.G. (1973). Social and endocrine determinates of sexual behaviour in siman and prosimian females. In: C.H. Phoenix (Editor). Primate Reproductive Behaviour: Symposium of the Fourth Congress of the International Primatological Society, vol. 2, S. Karger, Basel.

Feeroz, M.M. (1999). The ecology and behaviour of the Pig-tailed Macaque (Macaca leonina) in Bangladesh. Unpubl. Ph.D Thesis. University of Cambridge, Cambridge.

Fleagle, J.G. (1976). (1988). Primate Adaptation and Evolution. Academic Press, London.

Fooden, J. (1975). Taxonomy and evolution of Lion-tail and Pig-tail macaques (Primate: Cercopithecidae). Field. Zool. 67: 1-169.

Fooden, J. (1980). Classification and distribution of living Macaques. In: Lindburg, D. (editor). The Macaques: Studies in Ecology, Behaviour and Evolution, Van Nostrand Reinhold, New York.

Glick, B.B. (1980). Ontogenetic and psychobiological aspects of the mating activities of male Macaca radiata. In: Lindburg, D. (Editor). The Macaques: Studies in Ecology, Behaviour and Evolution. Van Nostrand Reinhold, New York.

Hadidian, I. and I.S. Bernstein (1979). Female reproductive cycles and birth data from an Old World monkey colony. Primates 20: 429442.

Kaufmann, J.H. (1965). A three-year study of mating behaviour in a free-ranging band of Rhesus Monkeys. Ecology 46: 500-512.

Kumar, A. (1987). The ecology and population dynamics of the Lion-tailed Macaque (Macaca silenus) in south India. Unpubl. Ph D thesis, University of Cambridge, Cambridge.

Kuehn, R.E., G.D. Jensen and R.K. Morill (1965). Breeding Macaca nemestrina: a pro a of birth engineering. Folia primatology 3: 251-62. Lindburg, D.G. (1971). The Rhesus Monkey in northern India: an ecological and behavioura study. In: L.A. Rosenblum (editor). Primate Behaviour Vol. 2. Academic Press, New York.

Lindburg, D.G. (1987). Seasonality of reproduction in primates. In: C. Mitchell and J. Erwin and A.R. Liss (editors). Comparative Primate Biology: Behavior, Cognition, and Motivation. Vol.2, part B, New York.

MacKinnon, J.R. (1997). Protected Areas Systems Review of the
Indo-malayan Realm. The Asian Bureau for Conservation Limited, England. pp. 69-73.

Mah, Y.L. (1980). The ecology and behaviour of Macaca fascicularis (Raffles). Unpublished Ph.D. Thesis. University of Malaya, Kuala Lumpur.

Matsumura, S. (1993). Female reproductive cycles and the sexual behaviour of Moor Macaques (Macaca maurus) in their natural habitat, south Sulawesi, Indonesia. Primates 34: 99-103.

Nadler, R.D. and L.A. Rosenblum (1973). Sexual behavior during successive ejaculations in Bonnet and Pig-tailed Macaques. American Journal Physical Anthropology 38: 217-20.

Oi, T. (1991). Non-copulatory mounting of wild Pig-tailed Macaques (Macaca nemestrina nemestrina) in West Sumatra, Indonesia. In: Ehara, A. (Editor). Primatology Today, pp.147-150. Elsevier Science Publishers.

Oi, T. (1996). Sexual behaviour and mating system of the wild Pigtailed Macaque in West Sumatra. In: Fa, J.E. and D.G. Lindburg (editors). Evolution and Ecology of Macaque Society, pp.342-368. Cambridge University Press, Cambridge.

Ridley, M. (1986). The number of males in a primate troop. Animal Behaviour 34: 1848-58.

Shiveley, C., S. Clarke, N. King, S. Schapiro and G. Mitchell (1982). Patterns of sexual behaviour in male macaques. American Journal of Primatology 2: 373-384.

Ross, C. (1992). Life history patterns and ecology of Macaque species. Primates 32: 207-215.

Taub, D.M. (1980). Female choice and mating strategies among wild Barbary Macaques (Macaca sylanus L.). In: Lindburg, D. (Editor). The Macaques: Studies in Ecology, Behaviour and Evolution. van Nostrand Reinhold, New York.

Taub, D.M. (1982). Sexual behaviour of wild Barbary Macaque males (Macaca sylvanus). American Journal of Primatology 2: 109-113.

Thierry, B. (1985). Patterns of agonistic interactions in three species of macaques (Macaca mulatta, M. fascicularis, M. tonkeana). Aggresive Behaviour 11: 223-233.

Tokuda, K., R.C. Simons and G.D. Jensen (1968). Sexual behavior in a captive group of Pig-tailed monkeys (Macaca nemestrina). Primates 9: 283-94 